\title{
Functional Role of the Secretin/Secretin Receptor Signaling During Cholestatic Liver Injury
}

\author{
Nan Wu, ${ }^{1 *}$ Leonardo Baiocchi, ${ }^{2 *}$ Tianhao Zhou, ${ }^{3}$ Lindsey Kennedy, ${ }^{1}$ Ludovica Ceci, ${ }^{1}$ Fanyin Meng, ${ }^{1,4}$ Keisaku Sato, ${ }^{1}$ \\ Chaodong Wu, ${ }^{5}$ Burcin Ekser (D) , ${ }^{6}$ Konstantina Kyritsi (D) , ${ }^{1}$ Debjyoti Kundu, ${ }^{1}$ Lixian Chen, ${ }^{1}$ Vik Meadows, ${ }^{1}$ Antonio Franchitto, ${ }^{7}$ \\ Domenico Alvaro, ${ }^{8}$ Paolo Onori, ${ }^{9}$ Eugenio Gaudio, ${ }^{9}$ Ilaria Lenci, ${ }^{2}$ Heather Francis, ${ }^{1,4}$ Shannon Glaser, ${ }^{3}$ and Gianfranco Alpini ${ }^{1,4}$
}

$\mathrm{L}$ iver diseases are a major health concern and affect a large proportion of people worldwide. There are over 100 types of liver disorders, including cirrhosis, cholangiocarcinoma (CCA), hepatocellular carcinoma, and hepatitis. Despite the relevant number of people who are affected by liver diseases, and the increased awareness with regard to these disorders, the number of deaths corresponding to liver injury is expected to increase in the foreseeable future. One of the possible reasons for this is that a complete comprehension of the mechanisms of hepatic damage involving specific liver anatomical districts is lacking, and, as a consequence, current treatments available are suboptimal. A major burden in the clinical setting are chronic cholestatic liver diseases (e.g., primary biliary cholangitis [PBC], primary sclerosing cholangitis [PSC], biliary atresia), which target the biliary epithelium and are characterized by cholestasis. ${ }^{(1,2)}$ Because the secretin $(\mathrm{Sct}) /$ secretin receptor (SR) axis (expressed only by cholangiocytes in the liver $)^{(3,4)}$ is the major regulator of ductal bile secretion, ${ }^{(5,6)}$ it is intuitive that this axis plays a key role in the maintenance of biliary homeostasis during the progression of cholangiopathies. For instance, $\mathrm{PBC}$ is characterized by reduced bicarbonate secretion, a phenomenon possibly impeding the formation of an $\mathrm{HCO}_{3}^{-}$canalicular film ("bicarbonate umbrella") on bile ducts, which has protective properties against highly concentrated bile acids (BAs). ${ }^{(1,7,8)}$ In this review, we examined the molecular mechanisms by which the Sct/SR axis regulates biliary function and the homeostasis of the biliary epithelium in normal and pathophysiological conditions.

\section{Sct/SR AXIS: THE BASICS}

Sct, a neuroendocrine, gastrointestinal peptide of 27 amino acids is secreted primarily by the intestinal $\mathrm{S}$ cells located in the Lieberkühn crypts. There is evidence that Sct is also secreted by other epithelia in different organs including the pancreas, intestine and liver, thus exerting various biological effects in

Abbreviations: $A C$, adenylyl cyclase; $A E 2$, anion exchanger 2; $A M A$, antimitochondrial antibody; $A S B T$, apical-sodium-BA cotransporter; $B A$, bile acid; BDL, bile duct ligated; cAMP, adenosine 3,5'-cyclic monophosphate; CCA, cholangiocarcinoma; CFTR, cystic fibrosis transmembrane conductance regulator; dnTGF- $\beta R I I$, dominant-negative transforming growth factor $\beta$ receptor II; $M d r 2$, multidrug resistance 2 (Abcb4); miRNA, microRNA; NGF, nerve growth factor; $P B C$, primary biliary cholangitis; $P K A$, protein kinase A; PSC, primary sclerosing cholangitis; Sct, secretin; $S M A D 2 / 3$, mothers against decapentaplegic homolog 2/3; SR, secretin receptor; TGF- $\beta 1$, transforming growth factor $\beta 1$.

Received May 26, 2020; accepted July 2, 2020.

*These authors contributed equally to this work.

Supported by the Senior Research Career Scientist Award (1IK6BX004601); Research Career Scientist Award (1IK6BX005226); VA Merit Awards from the United States Department of Veteran's Affairs Biomedical Laboratory Research and Development Service (1101BX001724, 1I01BX003031, and 5I01BX000574); U.S. National Institutes of Health (NIH) National Institute of Diabetes and Digestive and Kidney Diseases (DK108959, DK119421, DK115184, DK054811, DK076898, DK107310, DK110035, and DK062975); NIH National Institute on Alcohol Abuse and Alcoholism (AA025997 and AA025157); the Hickam Endowed Chair, Division of Gastroenterology and Hepatology, Department of Medicine, Indiana University School of Medicine; Indiana University Health-Indiana University School of Medicine Strategic Research Initiative; PSC Partners Seeking a Cure (460933-00001) portions of these studies were performed at the Central Texas Veterans Health Care System (Temple, TX), Richard L. Roudebush VA Medical Center (Indianapolis, IN), and Medical Physiology, Medical Research Building (Temple, TX). 
many systems. ${ }^{(9)}$ Important roles for Sct have been demonstrated with regard to regulation of fluid homeostasis. ${ }^{(10)}$ Stimulation of biliary secretion is due to Sct binding to the basolateral SR expressed only by cholangiocytes. ${ }^{(3)} \mathrm{SR}$ is a $\mathrm{G}$ protein-coupled receptor (GPCR) class B1 that contains seven membrane-spanning domains; members of the GPCR class B1 family characteristically activate their signal transduction pathway through increased adenosine 3',5'-cyclic monophosphate (cAMP) intracellular levels. ${ }^{(11,12)}$ In addition, Sct stimulates ductal secretory activity by activation of the $\mathrm{Ca}^{2+}$-dependent adenylyl cyclase (AC) isoforms, AC5, AC6, and AC9, the $\mathrm{Ca}^{2+} /$ calmodulin-stimulated $\mathrm{AC} 8$, and the soluble sAC, which are expressed in large cholangiocytes. ${ }^{(13)}$ Cholestatic liver diseases represent an important chapter of clinical hepatology. In this perspective, studies were undertaken over the last 50 years to identify the features of cholangiocytes and the molecular mechanisms of bile secretion by these cells in normal and cholestatic conditions.

\section{ROLE OF THE Sct/SR AXIS IN THE MODULATION OF DUCTAL BILE SECRETION IN NORMAL CONDITIONS}

The mechanism linking Sct to ductal secretion is as follows: Sct binds to SR on large cholangiocytes, increasing intracellular cAMP levels, which in turn stimulates phosphorylation of protein kinase A (PKA), opening of the cystic fibrosis transmembrane conductance regulator (CFTR), and activation of the apically located $\mathrm{Cl}^{-} / \mathrm{HCO}_{3}^{-}$exchanger AE2 (anion exchanger 2), leading to enhanced secretion of bicarbonate-rich choleresis. ${ }^{(3,5,14)}$ Further research clarified that Sct stimulates water and bicarbonate secretion only in large cholangiocytes lining the large bile ducts, but not small cholangiocytes lining the small ducts. ${ }^{(3,15)}$ This finding demonstrates that the dimensional heterogeneity of the biliary epithelium is linked to functional differences, as only large cholangiocytes express SR, CFTR, and AE2. ${ }^{(3,16)}$ Moreover, these cells are reactive to other gastrointestinal peptides/neuropeptides and neurotransmitters such as somatostatin, gastrin, and endothelin-1. ${ }^{(6)}$ Among nonhormonal regulators of biliary secretion, BAs need to be underscored. A number of studies show that SR, cAMP levels, and AE2 were all increased in large cholangiocytes exposed to a physiologic amount of taurocholic or taurolithocholic acids. ${ }^{(17)}$ The important interplay between the Sct/ SR axis and BAs, in supporting hepato-biliary secretion, was further confirmed by the individuation of a specific apical-sodium-BA cotransporter (ASBT) detected in cholangiocytes. ${ }^{(17)}$ ASBT is responsible for partial reuptake of BAs from bile, allowing their recirculation in blood in a short circuit within

(C) 2020 by the American Association for the Study of Liver Diseases.

View this article online at wileyonlinelibrary.com.

DOI 10.1002/hep.31484

Potential conflict of interest: Nothing to report.

\begin{abstract}
ARTICLE INFORMATION:
From the ${ }^{1}$ Hepatology and Gastroenterology, Medicine, Indiana University, Indianapolis, IN; ${ }^{2}$ Liver Unit, Department of Medicine, University of Rome "Tor Vergata,", Rome, Italy; ${ }^{3}$ Department of Medical Physiology, Texas A\&M University, Bryan, TX; ${ }^{4}$ Gastroenterology, Medicine, Richard L. Roudebush VA Medical Center and Indiana University, Indianapolis, IN; ${ }^{5}$ Department of Nutrition, Texas A\&M University, College Station, TX; ${ }^{6}$ Division of Transplant Surgery, Department of Surgery, Indiana University School of Medicine, Indianapolis, IN; ${ }^{7}$ Eleonora Lorillard Spencer Cenci Foundation, Rome, Italy; ${ }^{8}$ Department of Internal Medicine and Medical Specialties, Rome, Italy; ${ }^{9}$ Department of Anatomical, Histological, Forensic Medicine and Orthopedics Sciences, Sapienza University of Rome, Rome, Italy.
\end{abstract}

\title{
ADDRESS CORRESPONDENCE AND REPRINT REQUESTS TO:
}

Gianfranco Alpini, Ph.D.

Gastroenterology, Medicine, Richard L. Roudebush VA Medical

Center and Indiana University

1481 W. 10th Street
Constitution Wing, Room C-7151

Indianapolis, IN 46202

E-mail: galpini@iu.edu or gianfranco.alpini@va.gov 
the liver, thus increasing hepatocyte BA-dependent bile flow. ${ }^{(18)}$ Interestingly, Sct was demonstrated to stimulate migration of ASBT from the cytoplasmic to the canalicular membrane of cholangiocytes and to increase BA uptake from cholangiocytes, thus enhancing cholehepatic shunting. ${ }^{(19)}$ Taken together, it is intuitive that BA-dependent hepatocyte bile flow and BA-independent (regulated by the Sct/SR axis) cholangiocyte secretion are integrated in a complex interplay. With regard to small cholangiocytes, even if these cells lack SR, CFTR and AE2, an alternative mechanism to secrete water and electrolytes has been identified involving the activation of $\mathrm{Ca}^{2+}$ dependent pathways. ${ }^{(20)}$ Small mouse cholangiocytes have been shown to release adenosine triphosphate and to produce purinergic receptor-mediated bile secretion. ${ }^{(21)}$.This suggests the presence of an alternative, compensatory pathway in small cholangiocytes to maintain biliary homeostasis when larger bile ducts are damaged. ${ }^{(22,23)}$ However, when large cholangiocytes are injured, such as after carbon tetrachloride $\left(\mathrm{CCl}_{4}\right)$ treatment, small, mitotically dormant cholangiocytes proliferate, thus replacing and acquiring the phenotypic features of large cholangiocytes. ${ }^{(23)}$ Secretory pathways of large and small cholangiocytes are depicted in Fig. 1.

\section{Sct/SR AXIS IN EXPERIMENTAL ANIMAL MODELS OF CHOLESTASIS}

Cholestasis is a process exhibiting an early phase with intense "typical" cholangiocyte proliferation, possibly compensatory, followed by a second later stage represented by loss of bile ducts (ductopenia) and fibrosis, which is accompanied by an "atypical" proliferation. ${ }^{(24)}$ Accordingly, it seems important to examine the relationship between the Sct/SR axis and bile ducts with respect to these two different phases. In this section, the findings on the Sct/SR axis will be described with respect to hyperplastic or ductopenic experimental settings.

\section{Sct/SR Axis in the Early Hyperplastic Phase of Cholestasis}

The bile duct ligated (BDL) rodent model represents an important tool to evaluate the molecular mechanisms occurring in the early hyperplastic phase of cholestasis, also reproducing "ductular reaction" (a histological finding corresponding to proliferating ductules), which is frequently observed in liver specimens of human cholestatic diseases. ${ }^{(24)}$
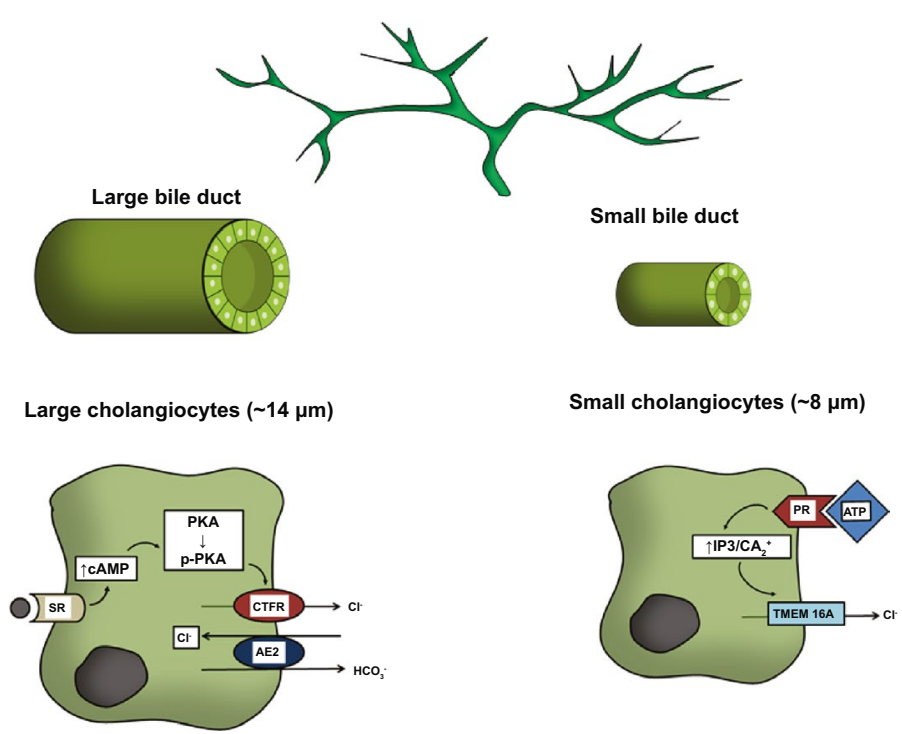

FIG. 1. Differences between large and small cholangiocytes in size, in the location within the biliary tree, and in the secretive pathway. As reported, small cholangiocytes are able to migrate and replace the large ones when the latter are damaged. Symbol: $\mathbf{O}$, secretin. Abbreviations: ATP, adenosine triphosphate; IP3, inositol trisphosphate; p-PKA, phosphorylated PKA; PR, purine receptor; TMEM16A, transmembrane member $16 \mathrm{~A}$. 
Pivotal studies using this experimental system demonstrated that Sct-stimulated bile secretion is linearly related to the degree of bile duct hyperplasia, and cholangiocytes isolated from BDL rats expressed SR at a rate that was higher compared with normal cholangiocytes. ${ }^{(4,25)} \mathrm{Up}$-regulation of the Sct/SR axis corresponded to increased synthesis of intracellular cAMP, which led to increased activation of PKA, opening of CFTR channels, and activation of AE2 with subsequent enhanced biliary secretion. ${ }^{(3,5,6,14,26)}$ In this setting, biliary cAMP levels have been shown to play a central role in promoting choleretic signaling. In fact, down-regulation or up-regulation of cAMP signaling by several gastrointestinal hormones and neurotransmitters, such as somatostatin, gastrin, endothelin-1, and the $\alpha 2$-adrenergic receptor agonists (as well as a number of BAs), proportionally changes ductal bicarbonate secretion. ${ }^{(6)}$ Moreover, during BDL-induced cholestasis, increased cAMP levels not only support choleresis, but also enhance the expansion of bile ducts. ${ }^{(6,15,27,28)}$ Proliferation of bile ducts is correlated with cAMP-dependent activation of ERK $1 / 2$ signaling; however, this mechanism is inhibited in BDL rodents lacking SR. ${ }^{(28,29)}$ Further studies clarified that cAMP-mediated proliferation in this setting is sustained by both autocrine (by large cholangiocytes) and paracrine (duodenal S cells) Sct secretion and is promoted by specific microRNAs (miR125b and let7a), which increase biliary mass and liver fibrosis by directly targeting vascular endothelial growth factor-A and nerve growth factor (NGF), respectively. ${ }^{(27)}$ Changes in large cholangiocyte phenotypes after BDL are depicted in Fig. 2.

\section{Sct/SR Axis in Ductopenic Models of Cholestasis}

Chronic cholestasis, in both humans and rodent models, is characterized by a ductopenic stage, with reduced biliary mass and progression to liver fibrosis. A transient ductopenic cholestatic model was induced in animals using toxins, such as $\mathrm{CCl}_{4}{ }^{\left({ }{ }^{23}\right)}$ $\mathrm{CCl}_{4}$ treatment induced selective damage and loss of Sct-stimulated secretory activity in large (but not small) cholangiocytes. ${ }^{(23)}$ Interestingly, the consequential loss of secretive and proliferative activities in large cholangiocytes was replaced by the expansion of small cholangiocytes, which de novo acquired

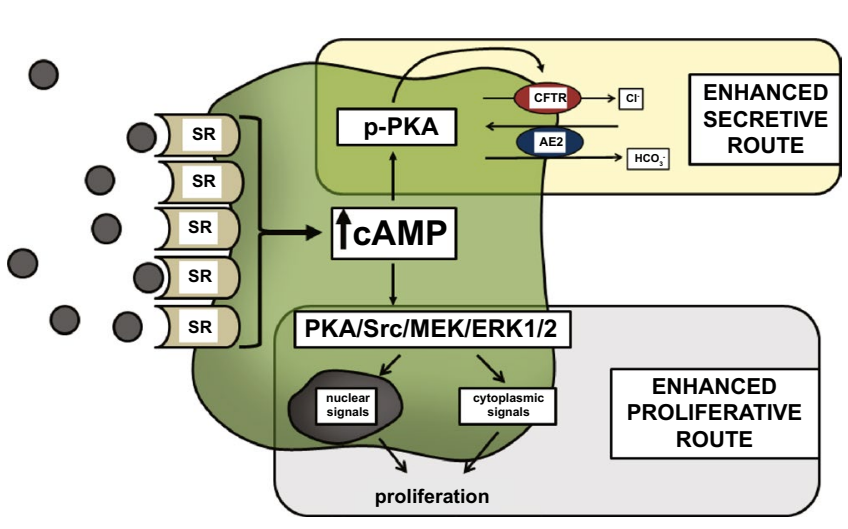

FIG. 2. Changes occurring in rat large cholangiocytes by BDLinduced cholestasis. The up-regulation of Sct/SR axis enhances cAMP accumulation in the cell, stimulating the secretive and proliferative activities. Symbol: $\mathbf{O}$, secretin. Abbreviations: ERK, extracellular receptor kinase; MEK, mitogen-activated protein kinase kinase; p-PKA, phosphorylated PKA; Src, proto-oncogene tyrosine-protein kinase.

the phenotypes of large cells. ${ }^{(23)}$ The relocation of Sct/SR axis from damaged (large) to nondamaged (small) cholangiocytes underscores the efforts of the biliary epithelium to maintain a pathway of paramount importance during injury. We suggest that small cholangiocytes typically display traits of committed progenitor cells and may act as a biliarycommitted progenitor niche that expands and differentiates to large cholangiocytes during cholestatic injuries in an effort to maintain secretive capacity and biliary homeostasis. ${ }^{(24)}$

\section{Sct/SR Axis in Animal Models Resembling Adult Human Chronic Cholestatic Liver Diseases}

$\mathrm{PBC}$ is an autoimmune disease that primarily affects middle-aged women, and is characterized by positive antimitochondrial antibodies (AMA) in the blood and potentially evolves toward extended liver fibrosis and cirrhosis. ${ }^{(30)}$ The target cells of human $\mathrm{PBC}$ are cholangiocytes lining the interlobular bile ducts (i.e., small ducts), with consequential necrosis, apoptosis, and progressive cholestasis. ${ }^{(31)} \mathrm{PBC}$, at the ultrastructural level, displays nonsuppurative cholangitis with portal inflammatory infiltrates consisting of autoreactive $\mathrm{T}$ cells surrounding bile ducts. $^{(31)}$ 


\section{Sct/SR AXIS IN PBC ANIMAL MODELS}

The lack of knowledge and effective medical treatments for PBC is also related to the existence of inadequate animal models. Lately, several systems based on genetically modified mice have been proposed. One of these models is represented by the dominantnegative transforming growth factor $\beta$ receptor II (dnTGF- $\beta$ RII) mouse, which exhibits AMA positivity, coupled with biliary inflammation and injury of small bile ducts. ${ }^{(32)}$ The Sct/SR axis was recently examined in an early-stage PBC mouse model (dnTGF- $\beta$ RII, 12 weeks) to establish the role of this pathway in biliary injury, liver inflammation, and fibrosis. ${ }^{(7)}$ This study demonstrated increased stimulation of Sct/SR signaling in this mouse model. Inhibition of SR signaling by the SR antagonist Sec5-27 decreased biliary senescence, liver inflammation, and fibrosis. Interestingly, in this model, contrary to what has been canonically observed, stimulation of Sct/SR signaling did not correspond to increased bicarbonate biliary secretion. This phenomenon, in parallel with what is observed in human PBC, possibly affects the formation of the protective bicarbonate umbrella ${ }^{(33)}$ at the canalicular side of the biliary system, which is likely associated with miR-506-mediated CFTR/AE2 decreased expression. The importance of AE2 stimulation by the Sct/SR molecular cascade of signals has been supported by observations in Ae2a, $\mathrm{b}^{-/-}$mice with disruption of the AE2 gene. ${ }^{(34)}$ This rodent model exhibits inflammatory liver damage and biochemical signs of progressive cholestasis and cytolysis coupled with AMA positivity, thus representing another suggested animal model to study PBC for its similarity with the corresponding human disease. ${ }^{(34)}$ Other rodent models of PBC have been described, such as IL- $2 \mathrm{R} \alpha^{-/-}$mice, which is a genetically modified strain that demonstrated $100 \%$ AMA positivity as well as mild bile duct injury, interface hepatitis, and severe colitis, although the latter not typically observed in patients with $\mathrm{PBC}{ }^{(35)}$ Another interesting model has been developed in mice by inducing chronic expression of interferon gamma (IFN- $\gamma$ ) by deletion of 3'-untranslated region adenylate uridylate-rich element within the IFN- $\gamma$ gene. ${ }^{(36)}$ This strain exhibits (1) 100\% AMA positivity, (2) increased levels of BAs, (3) female predominance, and (4) not only portal and lobular inflammation, but also granulomas (which are a specific feature of human PBC) at histological examination; however, changes of Sct/SR axis as a function of cholestatic liver damage have not been evaluated.

\section{Sct/SR AXIS IN PSC ANIMAL MODELS}

With regard to PSC, the absence of diagnostic markers for early detection, low prevalence, and difficulty in accessing the biliary tract in human patients stimulated the search for animal models to study this disease. ${ }^{(37)}$ Multidrug resistance 2 (Mdr2, i.e., Abcb4) gene knockout mice $\left(\mathrm{Mdr}^{-/-}\right)$is one system that is currently being used to study PSC. Ablation of this gene removes phospholipid secretion in bile, in turn counteracting the formation of mixed micelles in cooperation with BAs, a process that mitigates the cytopathic-detergent property of BAs. Because these mice mimic several key features of human PSC (including the development of cholangitis, irregular bile duct formation, and liver fibrosis), they are generally considered a suitable tool to study this disease. ${ }^{(38)}$ Moreover, pictures resembling high similarities with PSC have been described in patients with defects of the MDR3 gene: the homo$\log$ of mouse Mdr2. ${ }^{(39)}$ Using this model, a possible important role of the Sct/SR axis in liver fibrotic processes occurring in PSC was proposed. ${ }^{(40)}$ In fact, cholangiocytes isolated from $\mathrm{Mdr} 2^{-/-}$mice demonstrated a basal increase in Sct and SR gene expression that, in turn, was associated with the activation of transforming growth factor $\beta 1 /$ transforming growth factor $\beta 1$ receptor (TGF- $\beta 1 / \mathrm{TGF}-\beta 1 \mathrm{R}$ ) axis and mothers against decapentaplegic homolog $2 / 3$ (SMAD2/3) phosphorylation; the latter pathway is well known for promoting liver fibrosis through hepatic stellate cell activation. ${ }^{(41)}$ Moreover, a direct link between SR signaling and TGF- $\beta 1$ stimulation was achieved when the specific Sct inhibitor Sec 5-27 was administered to mice. In fact, suppression of the Sct/SR axis in $\mathrm{Mdr} 2^{-/-}$mice was associated with reduced activity of the TGF- $\beta 1 \mathrm{R} / \mathrm{SMAD} 2 / 3$ pathway and a subsequent decrease of liver collagen deposition. ${ }^{(41)}$ These findings were then extended in the same $\mathrm{Mdr} 2^{-/-}$mouse model that was crossed with mice containing SR gene disruption. ${ }^{(42)}$ The model of $\mathrm{Mdr} 2^{-/} / \mathrm{SR}^{-/-}$mouse confirmed the contribution of Sct/SR axis in supporting liver fibrosis, as evaluation of collagen deposition in liver tissues was markedly decreased in $\mathrm{Mdr} 2^{-/-}$mice with disruption of the SR gene. However, this model expanded these findings by demonstrating that 
cellular senescence (arrest of cell cycle under stress conditions) and neo-angiogenesis that are enhanced, together with fibrosis, in $\mathrm{Mdr} 2^{-/-}$mice were normalized by suppression of the SR gene in the same animals. On the basis of these findings, a possible mechanism starting from Sct and involving (1) SR, (2) neo-angiogenetic factors, and (3) cellular senescence to determine liver fibrosis in experimental PSC, was suggested for the first time.

\section{SCT/SR Axis in Adult Human Cholestatic Chronic Liver Diseases}

In the following subparagraphs, the findings regarding Sct/SR axis in human PBC and PSC experimental studies are reported.

\section{DATA ON Sct/SR AXIS IN HUMAN PBC}

The first evidence of Sct/SR pathway malfunction in PBC came from a number of studies that sequentially demonstrated reduced mRNA levels and decreased immune-reactivity for AE2 in the liver that was associated with mild Sct-stimulated bicarbonate secretion in patients with $\mathrm{PBC} .{ }^{(43)}$ On the basis of these findings, $\mathrm{PBC}$ damage in humans was hypothesized to be associated with a defect in the formation of bicarbonate protective film (i.e., bicarbonate umbrella) on the canalicular side. This layer is thought to be important in the prevention of cellular damage induced by detergent BAs. To better clarify the mechanism of AE2 scarce response to Sct during $\mathrm{PBC}$, the possible role of miRs was investigated. Because miR-506 was predicted, on the basis of the available data sets, to possibly target AE2, a study focused on the influence of this miR on AE2 was undertaken. ${ }^{(44)}$ In fact, miR-506 was overexpressed (>3-fold increase) in $\mathrm{PBC}$ livers in comparison with normal controls. The possible effects of miR-506 on AE2 was then examined in isolated bile duct cells (immortalized H69 line and primary PBC and normal cultures). These experiments showed that miR-506 directly inhibited AE2 expression and its response to Sct. A recent study specifically examined the Sct/SR axis in PBC early-stage liver tissue. ${ }^{(7)}$ Similar to what has been observed in dnTGF- $\beta$ RII mice, expression of Sct and SR were augmented in human specimens. Despite this, bicarbonate biliary secretion was reduced, supporting the view of the down-regulation of AE2 in this disease. However, this study also found that the Sct/SR axis promotes scar tissue deposition, up-regulating the TGF- $\beta 1 /$ TGF- $\beta 1 \mathrm{R}$ pathway. In fact, the expression of both TGF- $\beta 1$ and its receptor was enhanced in the liver of patients with early-stage PBC. Based on data in the human samples and dnTGF- $\beta$ RII mouse, it was hypothesized that liver damage during early-stage $\mathrm{PBC}$ was significantly related to the up-regulation of the Sct/SR axis (potentially compensatory), which in turn determined an increase in ductular reaction, cellular senescence, and fibrosis. Decreased AE2 expression and bicarbonate secretion may be occurring through secondary mechanisms in this setting. In this perspective, possible inhibitors of the Sct/SR axis might be considered beneficial for the treatment of human PBC.

\section{DATA ON Sct/SR AXIS IN HUMAN PSC}

Data on the Sct/SR axis in patients with PSC are insufficient. A correlative evaluation was carried out with human samples in a study involving primarily Mdr2 ${ }^{-/-}$mice. ${ }^{(40)}$ Similar to what is reported in early-stage PBC, increased expression of Sct, SR, TGF- $\beta 1$, and its receptor was seen in PSC liver tissue. However, these findings were extended to evaluate let-7a, which is known to be an important regulator of $\mathrm{NGF}^{(45)}$ In fact, down-regulation of let-7 increases secretion of NGF and neuronal tissue regeneration. In tune with this observation, increased Sct/SR expression was associated with reduced let-7a activity and subsequent increased NGF expression in human PSC. The consequential increase in NGF justifies the further onset of proliferation characterized by ductular reaction and evolution toward fibrosis. Again, as has been observed in early-stage $\mathrm{PBC}$, up-regulation of the Sct/SR axis in PSC may exert negative effects by promoting scar-tissue deposition and evolution to end-stage liver disease. 


\section{SCT/SR Axis in Other Human Diseases Targeting the Biliary Tree}

Few data are available with regard to the Sct/SR axis in human biliary diseases, other than PBC and PSC. Biliary atresia is a pediatric disorder affecting about 6 out of 100,000 newborns in the western world. Being the most important cause of severe cholestatic liver disease in children, biliary atresia is a progressive obliterative cholangiopathy, involving primarily large ducts. Therapy for biliary atresia is based on surgical approaches either with liver transplantation or Kasai procedure. The latter is based on the complete removal of the extra-hepatic portion of the biliary tract and the direct anastomosis of the gut at the base of the liver, where the smaller (less or not affected) bile ducts converge. Given the important choleretic effect of Sct, treatment with this hormone was hypothesized in the 1980s (in conjunction with the surgical treatment) as a potential therapeutic for biliary atresia. ${ }^{(46)}$ Lately, a possible impairment of the digestive hormone system in this disease (involving Sct and cholecystokinin excretion) was suggested in a case report. ${ }^{(46)}$ A fetus showing a gallbladder full of sludge at 34-week gestation (possibly evolving toward biliary atresia) was treated, shortly after the induction of a premature birth, with Sct and a cholecystokinin analogue. ${ }^{(46)}$ A short course of this treatment normalized bile flow and dissolved the sludge, thus preventing the possible onset of a chronic cholestatic disease in this child. Based on this observation, the authors suggested dysregulation of choleretic hormones as a possible factor inducing biliary atresia. Several attempts have been made to develop animal models mirroring the features of human biliary atresia; however, despite the efforts, an adequate animal system to evaluate the pathogenesis of this pediatric disease and to test therapeutic strategies is not available so far.

Finally, another important human liver disease affecting the biliary tract is CCA. Differently from other liver primary tumors, such as hepatocellular carcinoma, SR is expressed in human CCA. ${ }^{(47)}$ To clarify the possible role of Sct/SR axis in CCA, a study was undertaken on CCA cell lines (primarily $\mathrm{Mz}-\mathrm{ChA}-1$ ) and liver tissue. ${ }^{(4)}$ Unlike normal cholangiocytes, Sct inhibited CCA cell growth in culture, which was related to a failure in inducing an increase of the intracellular levels of cAMP, as observed in normal cholangiocytes. The inhibitory effect of Sct on CCA growth was then confirmed in an in vivo model of $\mathrm{BALB} / \mathrm{c}$ nude mice injected with $\mathrm{Mz}-\mathrm{ChA}-1$ cells. After 57 days, these mice when treated with Sct (intraperitoneal injection, $25 \mu \mathrm{g} / \mathrm{kg} /$ body weight every 3 days) had CCA tumors 3 times smaller in volume when compared with control. The peculiar inhibitory

TABLE 1. Main Studies Focusing on the Role of Sct/SR Axis in Specific Cholestatic Human Liver Diseases

\begin{tabular}{|c|c|c|c|}
\hline Disease & Experimental Approach & Findings & Referenc \\
\hline \multirow[t]{3}{*}{ PBC } & AE2 $a, b^{-/-}$mice (PBC model; AMA+) & $\begin{array}{l}\text { AE2 gene disruption induces inflammatory liver damage and biochemical signs } \\
\text { of progressive cholestasis }\end{array}$ & $(34)$ \\
\hline & Liver specimens of human PBC & miR-506 overexpression decreases the activity of AE2 & $(44)$ \\
\hline & $\begin{array}{l}\text { - dnTGF- } \beta R \| \text { mice (PBC model; AMA+) } \\
\text { - Liver specimens of human PBC }\end{array}$ & $\begin{array}{l}\text { - Inhibition of Sct/SR axis reduces biliary proliferation, inflammation, and } \\
\text { fibrosis } \\
\text { - Sct fails to stimulate choleresis, as miR-506 overexpression decreases the } \\
\text { activity of CFTR/AE2 }\end{array}$ & $(7)$ \\
\hline \multirow[t]{2}{*}{ PSC } & $\begin{array}{l}\text { - Mdr2 } 2^{-/-} \text {mice (PSC model) } \\
\text { - Liver specimens of human PSC }\end{array}$ & $\begin{array}{l}\text { Increased Sct/SR gene expression determines activation of TGF- } \beta 1 / T G F-\beta 1 R \text { axis } \\
\text { and SMAD2/3 phosphorylation }\end{array}$ & $(40)$ \\
\hline & $\begin{array}{l}\text { Mdr2 } 2^{-/} / \mathrm{SR}^{-/-} \text {mice (PSC model with SR } \\
\text { gene disruption) }\end{array}$ & $\begin{array}{l}\text { Disruption of SR gene reduces fibrosis, cellular senescence, and } \\
\text { neo-angiogenesis }\end{array}$ & $(42)$ \\
\hline Biliary Atresia & Case report & $\begin{array}{l}\text { Treatment with Sct and cholecystokinin analogue, shortly after birth, resolved } \\
\text { biliary sludge, possibly preventing evolution toward biliary atresia }\end{array}$ & $(50)$ \\
\hline CCA & $\begin{array}{l}\text { - } \text { CCA cell lines } \\
\text { - Liver specimens of human PSC } \\
\text { - BALB/c nude mice seeded with CCA cells }\end{array}$ & Stimulation of Sct/SR axis reduces tumor growth & $(48)$ \\
\hline
\end{tabular}

Note: The reference, experimental systems used, and the main findings of each single publication are reported and ordered according to the specific disease. 
effect of Sct on tumor growth was attributed to an erroneous coupling of SR with the G-protein $G \alpha_{i}$ (inhibitory) instead of the normal coupling with $\mathrm{G \alpha}_{\mathrm{s}}$. This study provided the first evidence of the possible role of Sct/SR system in modulating CCA growth. Results of main studies evaluating the Sct/SR axis in specific human diseases of the biliary tract are provided in Table 1.

\section{Summary and Future Perspectives}

As reported in this review, Sct is a gastrointestinal hormone that has a multitude of effects on both healthy and injured biliary epithelia. While the attention of liver researchers was, at the beginning, captured by the important effects of Sct on BA-independent ductal secretion, our knowledge has extended to recognizing a role for this hormone in regulating proliferation, cellular senescence, and fibrosis of the hepatic biliary compartment. These effects are obtained by the wide interaction of the Sct/SR pathway with growth factors, miRs, BAs, cellular transporters, and other biological components. Animal models of cholestasis (or cholangiocyte damage) remain of paramount importance to further clarify molecular features of this process; however, additional efforts should be undertaken in the future to translate animal findings to human pathological conditions. Discovery and adoption of more appropriate animal models that mimic human diseases and/or confirmation of animal data in human samples represent a promising strategy to achieve new therapeutic tools. Finally, an in-depth study of Sct-related biological effects would be relevant for other important nonbiliary liver diseases. In fact, the evidence of a cooperative role of Sct and scavenger receptor CD36 in lipid absorption and the finding of reduced fatty tissue deposition in Sct knockout mice ${ }^{(49)}$ suggest manipulation of Sct/SR pathway may mitigate liver diseases characterized by increased fatty deposition.

\section{REFERENCES}

1) van Niekerk J, Kersten R, Beuers U. Role of bile acids and the biliary $\mathrm{HCO}_{3}\left(^{-}\right)$umbrella in the pathogenesis of primary biliary cholangitis. Clin Liver Dis 2018;22:457-79.
2) Feldman AG, Sokol RJ. Neonatal cholestasis: emerging molecular diagnostics and potential novel therapeutics. Nat Rev Gastroenterol Hepatol 2019;16:346-60.

3) Alpini G, Roberts S, Kuntz SM, Ueno Y, Gubba S, Podila PV, et al. Morphological, molecular, and functional heterogeneity of cholangiocytes from normal rat liver. Gastroenterology 1996;110:1636-43.

4) Alpini G, Ulrich CD 2nd, Phillips JO, Pham LD, Miller LJ, LaRusso NF. Upregulation of secretin receptor gene expression in rat cholangiocytes after bile duct ligation. Am J Physiol Gastrointest Liver Physiol 1994;266:G922-G928.

5) Alpini G, Lenzi R, Sarkozi L, Tavoloni N. Biliary physiology in rats with bile ductular cell hyperplasia. Evidence for a secretory function of proliferated bile ductules. J Clin Invest 1988;81:569-78.

6) Kanno N, LeSage G, Glaser S, Alpini G. Regulation of cholangiocyte bicarbonate secretion. Am J Physiol Gastrointest Liver Physiol 2001;281:G612-G625.

7) Kennedy L, Francis H, Invernizzi P, Venter J, Wu N, Carbone M, et al. Secretin/secretin receptor signaling mediates biliary damage and liver fibrosis in early-stage primary biliary cholangitis. Faseb J 2019;33:10269-79.

8) Sasaki M, Sato Y, Nakanuma Y. An impaired biliary bicarbonate umbrella may be involved in dysregulated autophagy in primary biliary cholangitis. Lab Invest 2018;98:745-54.

9) Hacki WH. Secretin. Clin Gastroenterol 1980;9:609-32.

10) Chu JY, Lee LT, Lai CH, Vaudry H, Chan YS, Yung WH, et al. Secretin as a neurohypophysial factor regulating body water homeostasis. Proc Natl Acad Sci U S A 2009;106:15961-6.

11) Siu FK, Lam IP, Chu JY, Chow BK. Signaling mechanisms of secretin receptor. Regul Pept 2006;137:95-104.

12) Kato A, Gores GJ, LaRusso NF. Secretin stimulates exocytosis in isolated bile duct epithelial cells by a cyclic AMP-mediated mechanism. J Biol Chem 1992;267:15523-9.

13) Strazzabosco M, Fiorotto R, Melero S, Glaser S, Francis H, Spirli $\mathrm{C}$, et al. Differentially expressed adenylyl cyclase isoforms mediate secretory functions in cholangiocyte subpopulation. HePATOLOGY 2009;50:244-52.

14) Alpini G, Ulrich C, Roberts S, Phillips JO, Ueno Y, Podila PV, et al. Molecular and functional heterogeneity of cholangiocytes from rat liver after bile duct ligation. Am J Physiol Gastrointest Liver Physiol 1997;272:G289-G297.

15) Alpini G, Glaser S, Ueno Y, Pham L, Podila PV, Caligiuri A, et al. Heterogeneity of the proliferative capacity of rat cholangiocytes after bile duct ligation. Am J Physiol Gastrointest Liver Physiol 1998;274:G767-G775.

16) Alpini G, Glaser S, Robertson W, Rodgers RE, Phinizy JL, Lasater J, et al. Large but not small intrahepatic bile ducts are involved in secretin-regulated ductal bile secretion. Am J Physiol Gastrointest Liver Physiol 1997;272:G1064-G1074.

17) Alpini G, Glaser S, Ueno Y, Rodgers R, Phinizy JL, Francis $\mathrm{H}$, et al. Bile acid feeding induces cholangiocyte proliferation and secretion: evidence for bile acid-regulated ductal secretion. Gastroenterology 1999;116:179-86.

18) Xia X, Francis H, Glaser S, Alpini G, LeSage G. Bile acid interactions with cholangiocytes. World J Gastroenterol 2006;12: 3553-63.

19) Alpini G, Glaser S, Baiocchi L, Francis H, Xia X, LeSage G. Secretin activation of the apical $\mathrm{Na}$-dependent bile acid transporter is associated with cholehepatic shunting in rats. Hepatology 2005;41:1037-45.

20) Dutta AK, Khimji AK, Kresge C, Bugde A, Dougherty M, Esser $\mathrm{V}$, et al. Identification and functional characterization of TMEM16A, a Ca2+-activated $\mathrm{Cl}$ - channel activated by 
extracellular nucleotides, in biliary epithelium. J Biol Chem 2011;286:766-76.

21) Woo K, Sathe M, Kresge C, Esser V, Ueno Y, Venter J, et al. Adenosine triphosphate release and purinergic (P2) receptormediated secretion in small and large mouse cholangiocytes. Hepatology 2010;52:1819-28.

22) Pedemonte N, Galietta LJ. Structure and function of TMEM16 proteins (anoctamins). Physiol Rev 2014;94:419-59.

23) LeSage G, Glaser S, Marucci L, Benedetti A, Phinizy JL, Rodgers $\mathrm{R}$, et al. Acute carbon tetrachloride feeding induces damage of large but not small cholangiocytes from BDL rat liver. Am J Physiol Gastrointest Liver Physiol 1999;276:G1289-G1301.

24) Sato K, Marzioni M, Meng F, Francis H, Glaser S, Alpini G. Ductular reaction in liver diseases: pathological mechanisms and translational significances. Hepatology 2019;69:420-30.

25) Alpini G, Lenzi R, Zhai WR, Slott PA, Liu MH, Sarkozi L, et al. Bile secretory function of intrahepatic biliary epithelium in the rat. Am J Physiol Gastrointest Liver Physiol 1989;257: G124-G133.

26) Francis H, Glaser S, Ueno Y, LeSage G, Marucci L, Benedetti A, et al. cAMP stimulates the secretory and proliferative capacity of the rat intrahepatic biliary epithelium through changes in the PKA/Src/MEK/ERK1/2 pathway. J Hepatol 2004;41:528-37.

27) Glaser S, Meng F, Han Y, Onori P, Chow BK, Francis H, et al. Secretin stimulates biliary cell proliferation by regulating expression of microRNA $125 \mathrm{~b}$ and microRNA let7a in mice. Gastroenterology 2014;146:1795-1808.e1712.

28) Glaser S, Lam IP, Franchitto A, Gaudio E, Onori P, Chow BK, et al. Knockout of secretin receptor reduces large cholangiocyte hyperplasia in mice with extrahepatic cholestasis induced by bile duct ligation. Hepatology 2010;52:204-14.

29) Alvaro D, Onori P, Metalli VD, Svegliati-Baroni G, Folli F, Franchitto A, et al. Intracellular pathways mediating estrogen-induced cholangiocyte proliferation in the rat. Hepatology 2002;36:297-304.

30) Hohenester S, Oude-Elferink RP, Beuers U. Primary biliary cirrhosis. Semin Immunopathol 2009;31:283-307.

31) Poupon R. Primary biliary cirrhosis: a 2010 update. J Hepatol 2010;52:745-58.

32) Tsuda M, Zhang W, Yang GX, Tsuneyama K, Ando Y, Kawata K, et al. Deletion of interleukin (IL)-12p35 induces liver fibrosis in dominant-negative TGFbeta receptor type II mice. Hepatology 2013;57:806-16.

33) Beuers U, Hohenester S, de Buy Wenniger LJ, Kremer AE, Jansen PL, Elferink RP. The biliary $\mathrm{HCO}(3)(-)$ umbrella: a unifying hypothesis on pathogenetic and therapeutic aspects of fibrosing cholangiopathies. Hepatology 2010;52:1489-96.

34) Salas JT, Banales JM, Sarvide S, Recalde S, Ferrer A, Uriarte I, et al. Ae2a, b-deficient mice develop antimitochondrial antibodies and other features resembling primary biliary cirrhosis. Gastroenterology 2008;134:1482-93.

35) Hsu W, Zhang W, Tsuneyama K, Moritoki Y, Ridgway WM, Ansari AA, et al. Differential mechanisms in the pathogenesis of autoimmune cholangitis versus inflammatory bowel disease in interleukin-2Ralpha(-/-) mice. Hepatology 2009;49:133-40.
36) Bae HR, Leung PS, Tsuneyama K, Valencia JC, Hodge DL, $\mathrm{Kim} \mathrm{S}$, et al. Chronic expression of interferon-gamma leads to murine autoimmune cholangitis with a female predominance. Hepatology 2016;64:1189-201.

37) Fickert P, Pollheimer MJ, Beuers U, Lackner C, Hirschfield G, Housset $\mathrm{C}$, et al. Characterization of animal models for primary sclerosing cholangitis (PSC). J Hepatol 2014;60:1290-303.

38) Fickert P, Fuchsbichler A, Wagner M, Zollner G, Kaser A, Tilg H, et al. Regurgitation of bile acids from leaky bile ducts causes sclerosing cholangitis in Mdr2 (Abcb4) knockout mice. Gastroenterology 2004;127:261-74.

39) Benzimra J, Derhy S, Rosmorduc O, Menu Y, Poupon R, Arrive L. Hepatobiliary anomalies associated with ABCB4/MDR3 deficiency in adults: a pictorial essay. Insights Imaging 2013;4:331-8.

40) Wu N, Meng F, Invernizzi P, Bernuzzi F, Venter J, Standeford $\mathrm{H}$, et al. The secretin/secretin receptor axis modulates liver fibrosis through changes in transforming growth factor- $\beta 1$ biliary secretion in mice. Нepatology 2016;64:865-79.

41) $\mathrm{Hu} H \mathrm{H}$, Chen DQ, Wang YN, Feng YL, Cao G, Vaziri ND, et al. New insights into TGF- $\beta /$ Smad signaling in tissue fibrosis. Chem Biol Interact 2018;292:76-83.

42) Zhou T, Wu N, Meng F, Venter J, Giang TK, Francis H, et al. Knockout of secretin receptor reduces biliary damage and liver fibrosis in Mdr2(-/-) mice by diminishing senescence of cholangiocytes. Lab Invest 2018;98:1449-64.

43) Prieto J, García N, Martí-Climent JM, Peñuelas I, Richter JA, Medina JF. Assessment of biliary bicarbonate secretion in humans by positron emission tomography. Gastroenterology 1999;117:167-72.

44) Banales JM, Sáez E, Uriz M, Sarvide S, Urribarri AD, Splinter $\mathrm{P}$, et al. Up-regulation of microRNA 506 leads to decreased $\mathrm{Cl}^{-} / \mathrm{HCO}_{3}^{-}$anion exchanger 2 expression in biliary epithelium of patients with primary biliary cirrhosis. Hepatology 2012;56:687-97.

45) Li S, Wang X, Gu Y, Chen C, Wang Y, Liu J, et al. Let-7 microRNAs regenerate peripheral nerve regeneration by targeting nerve growth factor. Mol Ther 2015;23:423-33.

46) Isenberg JN, Schwartz MZ. Stimulation of bile output by gastrointestinal hormones following portoenterostomy for biliary atresia. J Pediatr Surg 1984;19:471-5.

47) Mavros MN, Economopoulos KP, Alexiou VG, Pawlik TM. Treatment and prognosis for patients with intrahepatic cholangiocarcinoma: systematic review and meta-analysis. JAMA Surg 2014;149:565-74.

48) Onori P, Wise C, Gaudio E, Franchitto A, Francis H, Carpino $\mathrm{G}$, et al. Secretin inhibits cholangiocarcinoma growth via dysregulation of the cAMP-dependent signaling mechanisms of secretin receptor. Int J Cancer 2010;127:43-54.

49) Sekar R, Chow BK. Secretin receptor-knockout mice are resistant to high-fat diet-induced obesity and exhibit impaired intestinal lipid absorption. FASEB J 2014;28:3494-505.

50) Michel E, Kilavuz O, Jager R, Nasir R. Biliary atresia due to delayed maturation of the gut hormones' system? Introducing a new treatment modality. J Perinat Med 2004;32:288-92.

Author names in bold designate shared co-first authorship. 